\title{
Intra-annual stem diameter growth of Tamarix ramosissima and association with hydroclimatic factors in the lower reaches of China's Heihe River
}

\author{
ShengChun XIAO*, HongLang XIAO, XiaoMei PENG, QuanYan TIAN \\ Key Laboratory of Ecohydrology of Inland River Basin, Cold and Arid Regions Environmental and Engineering Research Institute, \\ Chinese Academy of Sciences, Lanzhou 730000, China
}

\begin{abstract}
High-resolution observations of cambial phenology and intra-annual growth dynamics are useful approaches for understanding the response of tree growth to climate and environmental change. During the past two decades, rapid socioeconomic development has increased the demand for water resources in the oases of the middle reaches of the Heihe River in northwestern China, and the lower reaches of the Heihe River have changed from a perennial river to an ephemeral stream with a decreased and degraded riparian zone. Tamarisk (Tamarix ramosissima) is the dominant shrub species of the desert riparian forest. In this study, the daily and seasonal patterns of tamarisk stem diameter growth, including the main period of tree ring formation, were examined. Observations concerning the driving forces of growth changes, along with implications for the ecology of the dendrohydrological area and management of desert riparian forests in similar arid regions, are also presented. The diurnal-seasonal activity of stem diameter and the dynamics of growth ring formation were studied using a point dendrometer and micro-coring methods during the 2012 growing season in shrub tamarisk in a desert riparian forest stand in the lower reaches of the Heihe River in Ejin Banner, Inner Mongolia of northwestern China. Generally, the variation in diurnal diameter of tamarisk was characterized by an unstable multi-peak pattern, with the cumulative stem diameter growth over the growing season following an S-shaped curve. The period from late May to early August was the main period of stem diameter growth and growth-ring formation. Among all of the hydroclimatic factors considered in this study, only groundwater depth was significantly correlated with stem diameter increment during this period. Therefore, for the dendrochronological study, the annual rings of the tamarisk can be used to reconstruct processes that determine the regional water regime, such as river runoff and fluctuations in groundwater depth. For the management of desert riparian forests, suitable groundwater depths must be maintained in the spring and summer to sustain tree health and a suitable stand structure.
\end{abstract}

Keywords: Tamarix ramosissima; stem diameter growth; tree ring formation; hydroclimatic factors; diurnal-seasonal scale; Heihe River

Citation: ShengChun XIAO, HongLang XIAO, XiaoMei PENG, QuanYan TIAN. 2014. Intra-annual stem diameter growth of Tamarix ramosissima and association with hydroclimatic factors in the lower reaches of China's Heihe River. Journal of Arid Land, 6(4): 498-510. doi: 10.1007/s40333-013-0248-x

Tree-ring growth series have been used to construct high-resolution proxies for changes in climactic and environmental processes, thereby providing important insights into the ecological evolution of arid regions around the world. In addition to studying the relationships between tree stem growth and environmental factors, the reliability of dendrochronological proxies for climate change have been examined ( $\mathrm{Li}$ et al.,
2008; Mäkinen et al., 2008; Nojd et al., 2008; Downes et al., 2009). Understanding how and when plants produce their annual structures during the growing season and how plants react to environmental stresses in natural systems from the tropics to the northern tree limits is therefore of great interest (Downes et al., 2002). High-resolution observations of cambial phenology and intra-annual growth dynamics are

\footnotetext{
*Corresponding author: ShengChun XIAO (E-mail: xiaosc@lzb.ac.cn) Received 2013-06-27; revised 2013-07-29; accepted 2013-08-11

(c) Xinjiang Institute of Ecology and Geography, Chinese Academy of Sciences, Science Press and Springer-Verlag Berlin Heidelberg 2014
} 
useful approaches for understanding the response of tree growth to climate change (Herzog et al., 1995; Deslauriers et al., 2007; Rossi and Deslauriers, 2007; Drew and Downes, 2009). Automatic point or band dendrometers have traditionally been used for continuous monitoring of stem radial variation throughout the year and for determining seasonal tree growth (Fritts, 1962; Herzog et al., 1995; Tardif et al., 2001; Bouriaud et al., 2005; Rossi and Deslauriers, 2007). These studies were conducted primarily on conifers and broadleaves, and few studies are available for tree species in desert areas, especially for shrubs.

Temporal dynamics of cambial activity and xylem development can also be monitored throughout the growing season by repeatedly extracting wood samples at short intervals (Antonova and Stasova, 1993, 1997; Bäucker et al., 1998; Deslauriers et al., 2003; Rossi et al., 2006a). This method enables direct observation of the periodic process of cambial activity and tracheid differentiation (Plomion et al., 2001; Vaganov et al., 2006) and is thought to represent the most reliable technique for monitoring wood formation (Rossi and Deslauriers, 2007; Mäkinen et al., 2008).

Annual growth rings in the wood archive the effects of the dominant environmental factors present during wood formation. To discover and interpret the relationships between climatic factors and individual developmental processes, it is important to understand the dynamics of cambial activity and the development of cells in the wood (García-González and Eckstein, 2003; Frankenstein et al., 2005; Fonti et al., 2007). Recent investigations into wood formation on a cellular level in other tree species (primarily conifers) have confirmed the importance of this knowledge for dendroclimatological and dendroecological studies (Antonova and Stasova, 1993; Horacek et al., 1999; Schmitt et al., 2000, 2004; Deslauriers et al., 2003; Rossi et al., 2006b, 2007; Marion et al., 2007).

Tamarisk (Tamarix ramosissima) is the dominant shrub species of desert riparian forests in northwestern China. The lower portion of the Heihe River is among the three main areas of tamarisk in China. During the past two decades, rapid socioeconomic development has increased the demand for water resources in the oases of the middle reaches of the Heihe River, and the lower reaches of the river have changed from a perennial river to an ephemeral stream. As a result, the riparian forests have decreased and become degraded in the lower reaches.

To the best of our knowledge, stem diameter activity and wood formation have not yet been studied in tamarisk in the lower reaches of the Heihe River in northwestern China. Our research was conducted on two main branches and several one-year-old branches of tamarisk at a riparian forest site with the following objectives: (1) to measure the variations in stem diameter growth that occur at daily to seasonal scales and to identify the main period of tree ring formation; (2) to assess the relationships between changes in stem diameter and meteorological and environmental factors at daily to seasonal scales; and (3) to present several implications related to the accurate extraction of information on climatic and environmental evolution from the data recorded in annual rings and the role of this information in making decisions regarding water resources management.

\section{Study area}

The study was carried out at a riparian forest site in the Ejin Nature Protection Area (approximately $42^{\circ} 01^{\prime} \mathrm{N}, 101^{\circ} 03^{\prime} \mathrm{E}$; $927 \mathrm{~m}$ asl) in the lower reaches of the Heihe River, northwestern China (Fig. 1). The predominant tree species in this region are Euphrates poplar (Populus euphratica) and shrub tamarisk. The

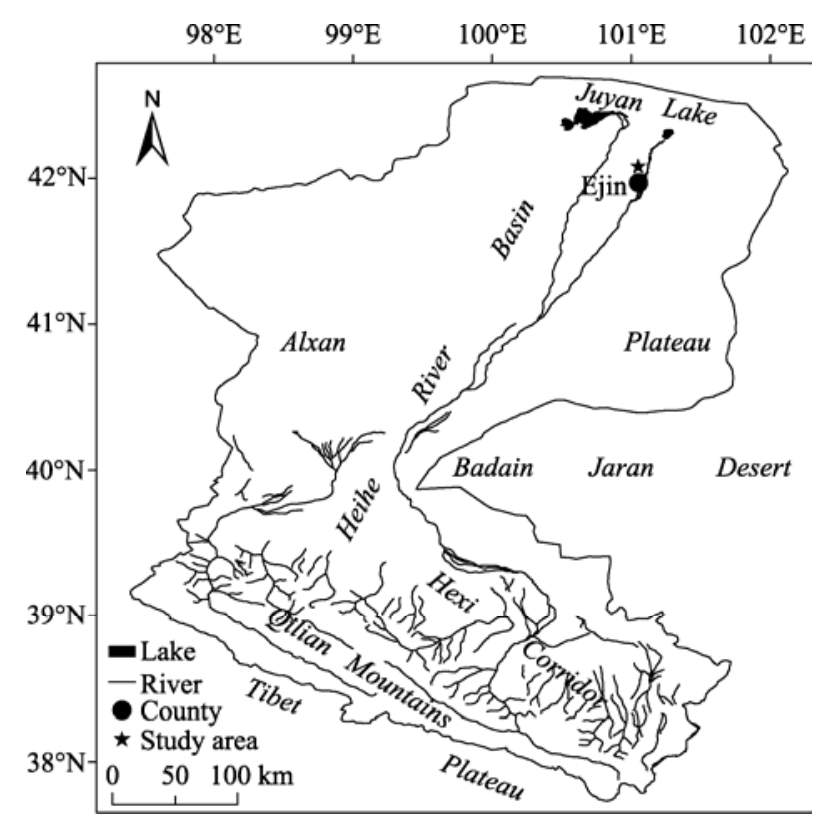

Fig. 1 Location of the study area 
Euphrates poplar grows mainly along the riverside, while the tamarisk grows parallel and outside of the Euphrates poplar.

The study area has an extremely arid continental climate. It is characterized by an annual mean temperature of $8.8^{\circ} \mathrm{C}$ (a minimum of $-11.7^{\circ} \mathrm{C}$ in January (the coldest month) and a maximum of $27.0^{\circ} \mathrm{C}$ in July (the hottest month)) and a mean annual precipitation of $37.1 \mathrm{~mm}$ (long-term means from 1957-2012 acquired from the Ejin meteorological station, $8 \mathrm{~km}$ from the study area).

The shrub land was clear cut in 2004. The stand density ranged from 100 to 150 clumps $/ \mathrm{hm}^{2}$. Clump crown diameter averaged $2 \mathrm{~m} \times 2 \mathrm{~m}$, and clump height ranged from 1.0 to $1.5 \mathrm{~m}$. Groundwater depth varied from 0.5 to $2.0 \mathrm{~m}$ in 2012. The zonal soil type is a grey desert soil, and the soil in the riparian forest is a tugaic soil (Xiao and Xiao, 2007).

\section{Materials and methods}

\subsection{Branches and environmental parameters}

Two branches of tamarisk in the forest, with diameters of $3 \mathrm{~cm}$ and $2 \mathrm{~cm}$ from the ground, were selected for monitoring and marked as $\mathrm{H} 1$ and $\mathrm{H} 2$, respectively. A diameter dendrometer (Ecomatik, Munich, Germany) was installed in the branches approximately $20 \mathrm{~cm}$ above the ground in early May 2012. The output of the sensor, with a resolution of $2 \mu \mathrm{m}$, was logged at 1-minute intervals and stored as 30-min averages using a datalogger. The ambient environmental variables (air temperature, relative humidity and groundwater depth) were measured using a micrometeorology station (ICT, Australia) and a 3001 LT Levelogger Gold monitor (Solinst, Georgetown, Ont., Canada) in a well (3 $\mathrm{m}$ in depth); recordings were made at 30-min intervals. The mean air temperature and groundwater depth were calculated by averaging all daily measurements (48 values/day).

\subsection{Data analysis}

Following the methods of Deslauriers et al. (2007) and Turcotte et al. (2009), the daily variations in tree radius were partitioned into three distinct phases. The daily stem radial increment $(\Delta R)$ was calculated from the dendrometer data; $\Delta R$ was defined as the part of the stem's circadian cycle when the stem radius exceeded the morning maximum until the subsequent maximum was reached generally in the following day.
To evaluate the types of diurnal variation and the stability over the entire tamarisk growing season, daily series were standardized by the daily minimum value. Standardized values and coefficients of variation were analyzed at different time nodes of the daily cycle in different months. The main growth period was determined based on the characteristics of the stem radius cumulative growth curve.

Pearson's correlation coefficients were calculated for the relationships between ambient environmental variables (air temperature and its maximum, mean and minimum, and groundwater depth) and both stem diameter changes and $\Delta R$ series extracted from dendrometer records on a diurnal to seasonal scale.

\subsection{Micro-cores sampling and processing}

Because the main branches of the shrub were too thin for repeated extraction of micro-cores, three one-year-old branches were selected randomly and cuttings of $2 \mathrm{~cm}$ long were removed every 15 days during the growing season, from early May to late October in the sampling plot. Collected samples were prepared for light microscopy.

Immediately after extraction, the 2-cm sections of branches were placed in glass tubes with FAA (alcohol (70\%)-aceto-formallin (37\%) solution at a ratio of 90:5:5). In the lab, the branch sections were embedded in paraffin. Transverse wood sections, with a thickness of 10-15 $\mu \mathrm{m}$, were cut on a rotary microtome (Kedi Instrument Equipment Co. Ltd., China) and stained with safranine and astrablue. Staining makes unlignified cells appear blue, whereas lignified cells turn red (Schweingruber, 2007). Under a light digital microscope (OLYMPUS CX31, Olympus America INC., USA) at $\times 20-40$ magnifications, the slice was photographed to enable description of the wood formation process. Because the sample cuttings were taken from different branches, the temporal dynamics of cell division and the widths of the branches were not compared to each other over the growing season.

\section{Results}

\subsection{Variation in tamarisk stem diameter}

\subsubsection{Diurnal cycle of stem diameter}

Typical diurnal cycles of stem shrinking and swelling are depicted in Fig. 2. In general, changes in stem radius showed a marked diurnal pattern, with the mini- 
mum stem radius observed in the late afternoon and early evening. Subsequently, the xylem expanded to reach the maximum stem radius in the early morning. Many untypical diurnal cycle patterns were observed, with some cycles having multi-maximum and minimum points or with the timing of these points deviating from the typical cycle.

The daily cycle of tree radius variation could be divided into three distinct phases: (1) a contraction phase (CP), which represents the period between the first maximum radius and the subsequent minimum radius; (2) an expansion phase (EP), representing the period from the minimum radius during a day to the subsequent maximum radius; and (3) a radial increment phase (IP), which represents an expansion phase from the time when the stem radius exceeds the first maximum radius until the subsequent maximum radius. Thus, each cycle of radial growth is comprised of a contraction phase, followed by an expansion phase and a radial increment phase. Positive or negative changes in the radius $(\Delta R)$ represent changes in which the maximum amplitude from the previous cycle was or was not reached, respectively. If the previous cycle's maximum was not reached, a negative radius change $(\Delta R-)$ was calculated and no increment phase was defined. In contrast, if the third phase was present, the difference in radius between the beginning of the third phase and the maximum expansion represented a positive change $(\Delta R+)$.

The results for H1, showing typical diurnal stem changes in June and July with the daily maximum occurring from 7:00 to 10:00 and the minimum from 14:00 to 16:00, are given in Fig. 3. In these two months, average diurnal stem changes varied from 40 to $51 \mu \mathrm{m}$, with standard deviations of 28 and $33 \mu \mathrm{m}$, and coefficients of variation ranging from 0.66 to 0.70 (Table 1). Coefficients of variation varied very little from 8:00 to 15:00, demonstrating that the contracting process was very stable. The average diurnal change in May was $240 \mu \mathrm{m}$, with a standard deviation of 177 $\mu \mathrm{m}$ and a coefficient of variation of 1.17 (Table 1 ). The diurnal changes are characterised by multiple peaks and increasing values. The large standard deviation and coefficient of variation indicate that the pattern of diurnal changes is unstable during this time period. The multi-peak patterns, lower average diurnal changes and large coefficients of variation in August, September and October indicate that the contraction and expansion phases of the diurnal cycle are unstable during this time (Fig. 3, Table 1).

3.1.2 Stem diameter variation and environmental parameter changes during the growing season

The cumulative stem radial growth curves of both samples followed an S pattern (Fig. 4a), with an increase from early May to early August, followed by changes ranging from a slower increase to a slight decrease through the end of the growing season. The curves could be divided into three periods. The first period, with a slow growth rate, occurred before mid May. The second period, which lasted from mid May

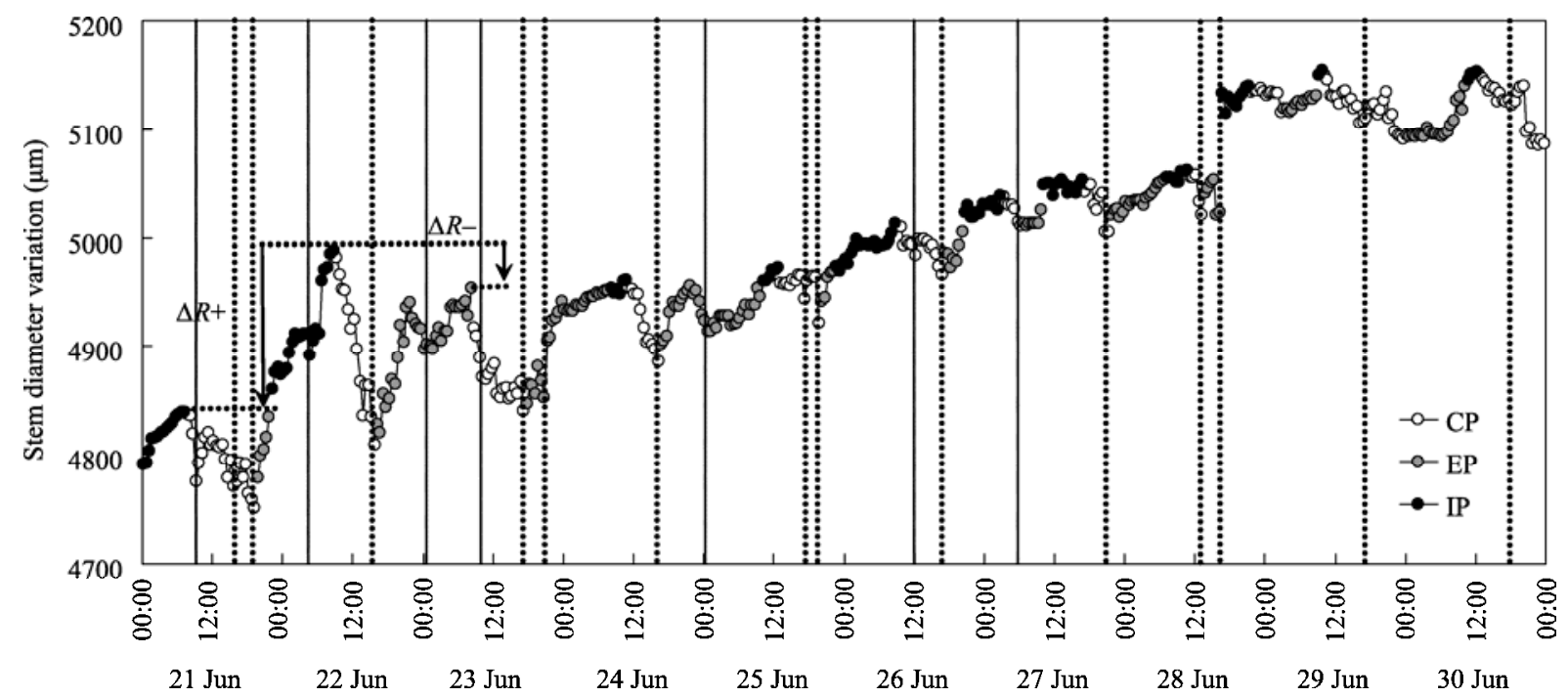

Fig. 2 Diurnal changes in tamarisk stem diameter and phase divisions. Vertical dotted lines show the time at which the normal minimum occurred; vertical solid lines show when other minima occurred. CP, contraction phase; EP, expansion phase; IP, increment phase. 

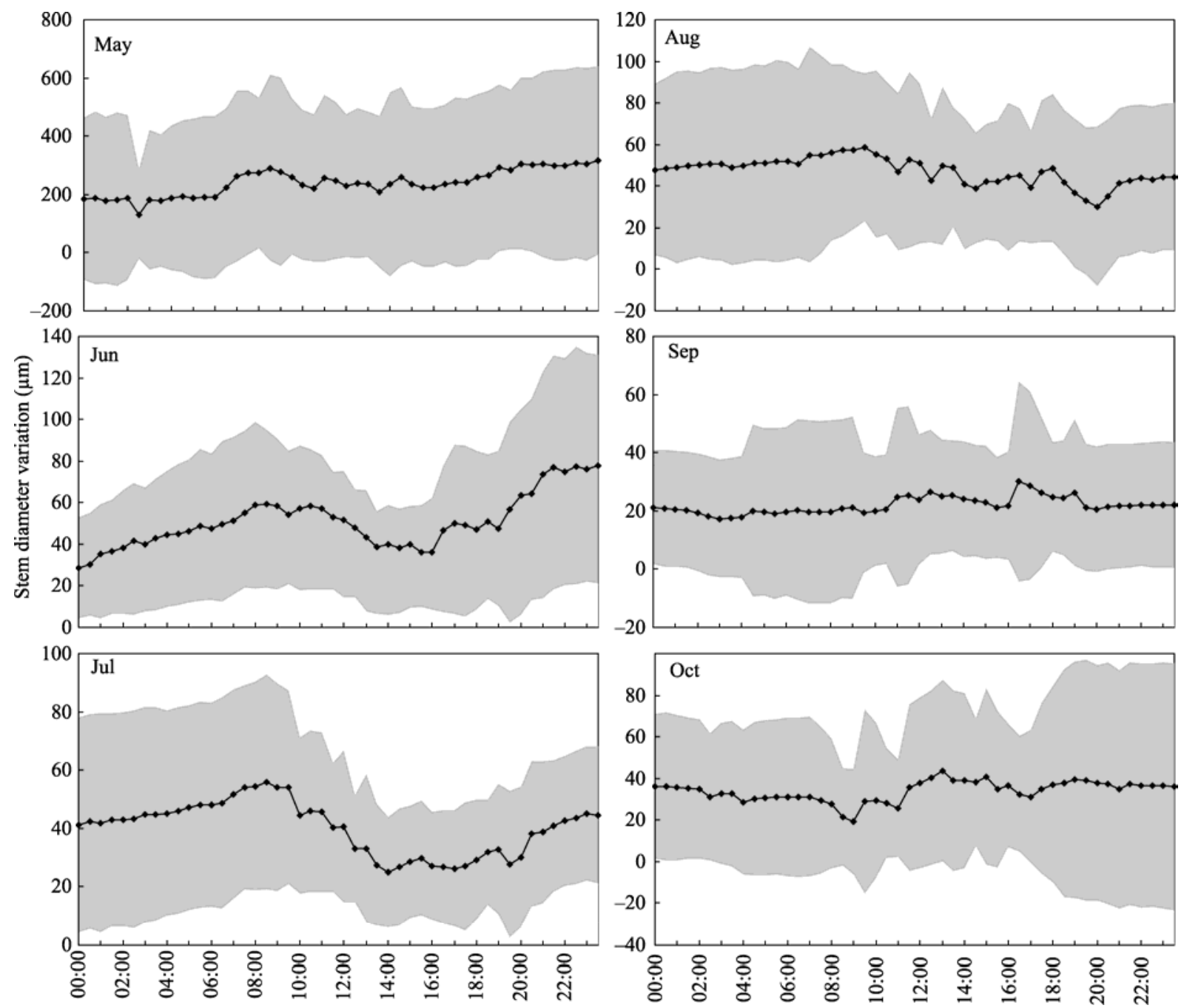

Fig. 3 Patterns of diurnal variation in tamarisk stem diameter during the growing season (example of $\mathrm{H} 1$; the shadow indicates the range of the standard variation)

Table 1 Mean daily increment in stem diameter from May to October

\begin{tabular}{lcccccc}
\hline & May & June & July & August & September & October \\
\hline Mean $(\mu \mathrm{m})$ & 240 & 51 & 40 & 47 & 22 & 34 \\
Standard deviation $(\mu \mathrm{m})$ & 281 & 33 & 28 & 39 & 24 & 41 \\
Coefficient of variation & 1.17 & 0.66 & 0.70 & 0.83 & 1.08 & 1.21 \\
\hline
\end{tabular}

to early August, was the period of most rapid radial stem growth, with mean rates of 77.42 and 17.47 $\mu \mathrm{m}$ /day for samples $\mathrm{H} 1$ and H2, respectively. During the third period, which lasted from early August to the end of the growing season, the stem radial growth rate decreased gradually and sometimes became negative, with mean rates of -1.08 to $0.05 \mu \mathrm{m}$ /day for samples $\mathrm{H} 1$ and H2, respectively (Fig. 4b). In the early growing season, the tamarisk stem diameter daily incre- ment $(\Delta R)$ exhibited large changes in amplitude. During the main growth period (from late May to early August), $\Delta R$ was primarily positive $(\Delta R+)$ and accounted for $78 \%$ and $80 \%$ of the entire $\Delta R$ for $\mathrm{H} 1$ and H2, respectively (Fig. 4b). By the end of May and into June 2012, growth ring formation was 50\% and 90\% complete for $\mathrm{H} 1$ and $\mathrm{H} 2$, respectively. During the 2012 growing season, the stem diameter growth of H1 and $\mathrm{H} 2$ was 4.72 and $0.87 \mathrm{~mm}$, respectively. 

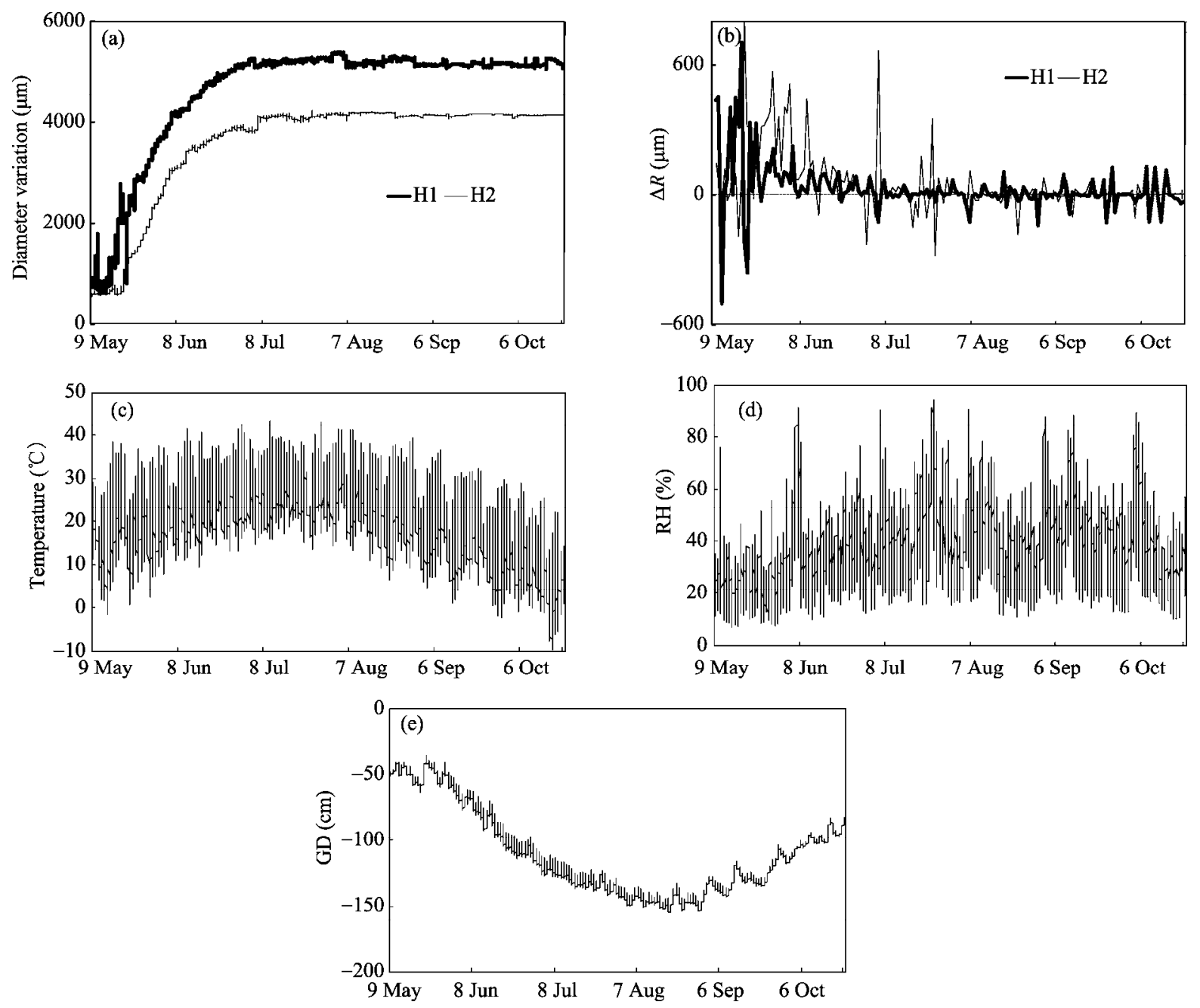

Fig. 4 Variation in stem diameter (a) and daily increments $(\Delta R ; \mathrm{b})$ of tamarisk for the samples $\mathrm{H} 1$ and $\mathrm{H} 2$ (grey boxes represent the main stem growing period), and the changes in environmental parameters at the study area (c, air temperature; d, relative humidity; e, groundwater depth) during the growing season

The air temperatures, relative humidity and groundwater depths for the study plot in the 2012 growing season are given in Figs. 4c, d and e, respectively. The mean, maximum and minimum air temperature in May was $19.3^{\circ} \mathrm{C}, 38.4^{\circ} \mathrm{C}$ and $-1.4^{\circ} \mathrm{C}$, respectively. In July, the air temperature increased, with a mean, maximum and minimum of $26.9^{\circ} \mathrm{C}, 43.4^{\circ} \mathrm{C}$ and $13.5^{\circ} \mathrm{C}$, respectively. In September, the mean air temperature decreased to $16.1^{\circ} \mathrm{C}$, with a minimum air temperature below zero, $-2.2^{\circ} \mathrm{C}$. The monthly mean relative humidities were $22.1 \%$, $34.1 \%, 41.3 \%$, 36.6\%, $41.4 \%$ and $36.2 \%$ from May to October 2012. The groundwater depth was highest in the spring, measuring approximately $-50 \mathrm{~cm}$, and deceased to the lowest level in early August, measuring approximately -150 cm. From May to October, total precipitation was 31.1 mm over 13 rainfalls; two heavy rainfalls of $8.3 \mathrm{~mm}$ and $8.9 \mathrm{~mm}$ occurred on 6 June and 24 July, respectively, while all other rainfalls resulted in less than 3.0 mm of precipitation.

\subsection{Relationships between variation in tamarisk stem diameter and environmental factors}

\subsubsection{Relationships at the diurnal scale}

At the diurnal scale, variation in stem radius was correlated with environmental factors, with the correlation changing from positive to negative at 48 time points (Fig. 5). For sample H1, the air temperature showed a primarily negative correlation with stem radial variation in the period from late May to mid August, but showed a positive correlation during other periods. The influence of the relative humidity on 
variation in stem radius was opposite to that of air temperature. The groundwater depths were positively correlated with stem radial variation during mid June to mid September but were negatively correlated during the earlier and later periods of the growing season. Sample $\mathrm{H} 2$ primarily showed a positive correlation with air temperature and a negative correlation with relative humidity over the entire growing season.
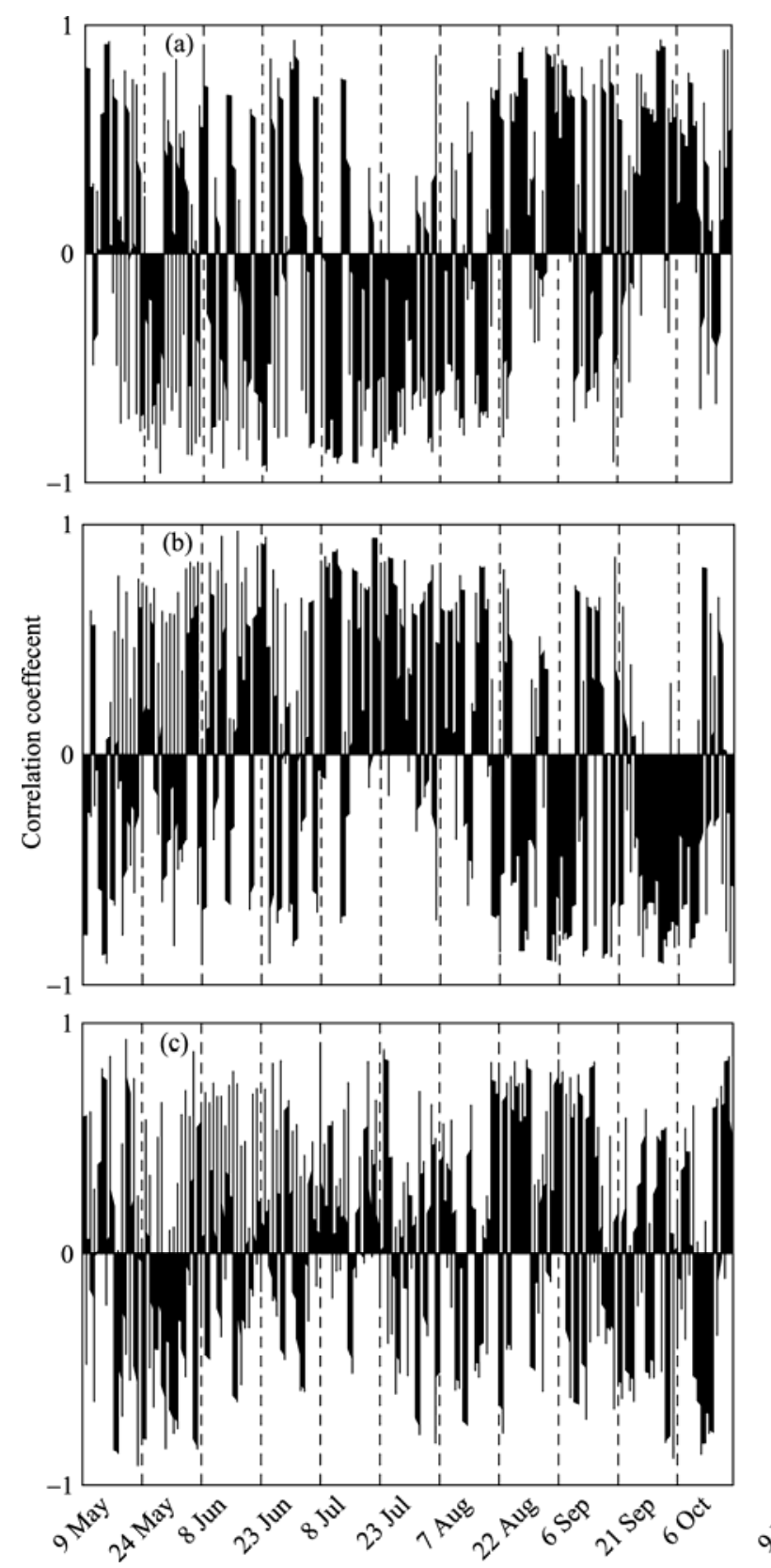

\subsubsection{Relationships at the seasonal scale}

Relationships between stem diameter increments $(\Delta R)$, extracted from the dendrometer record, and environmental variables (climate variables and groundwater depth) at the study plots are depicted in Fig. 6. At the seasonal scale, the three air temperature parameters were positively correlated with $\Delta R$ for the two samples during the early growing season from early to
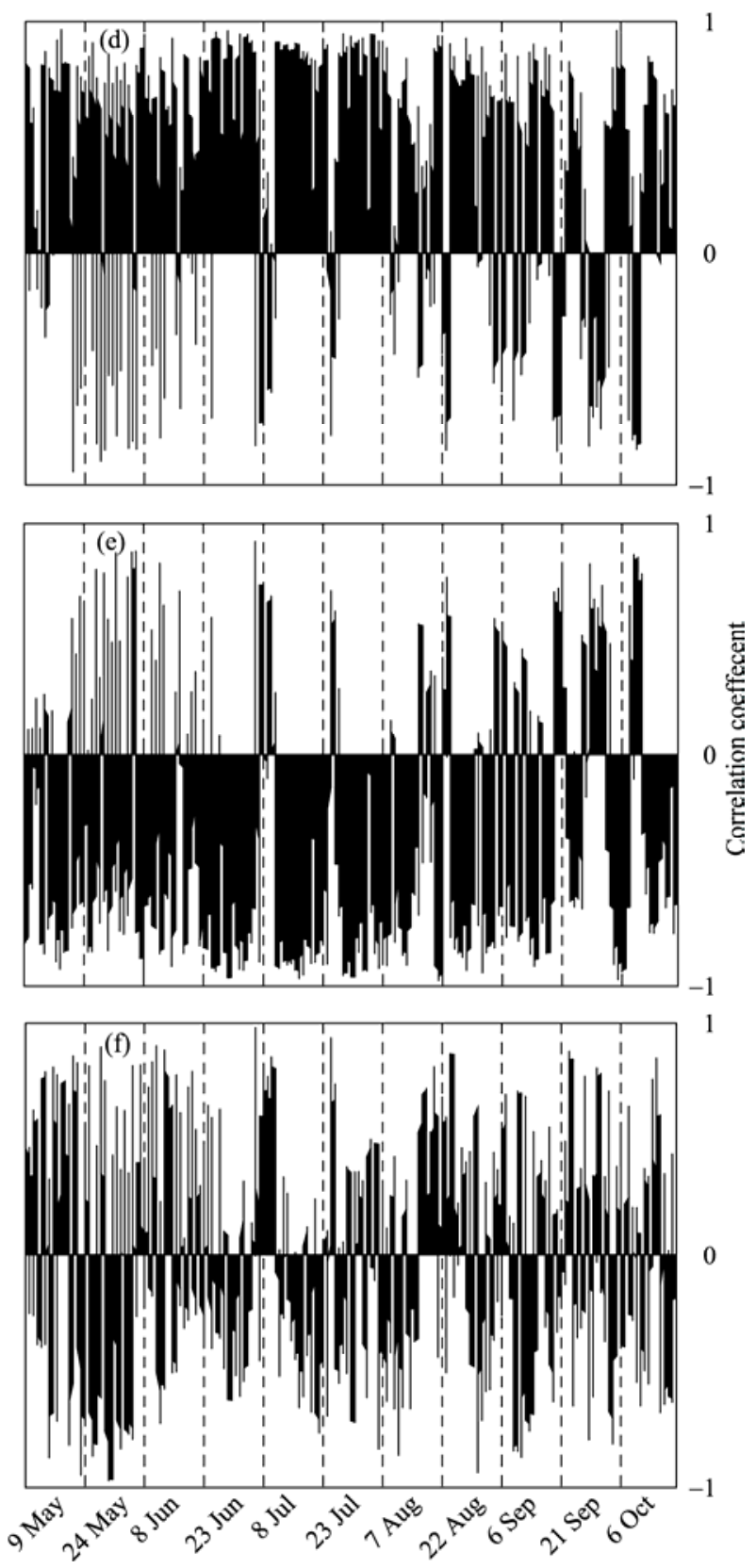

Fig. 5 Correlations between the changes in tamarisk stem diameter and environment factors (left and right columns show the results for $\mathrm{H} 1$ and $\mathrm{H} 2$, respectively; the three rows show the results for air temperature, relative humidity and the groundwater depth, respectively; 48 values/day) 

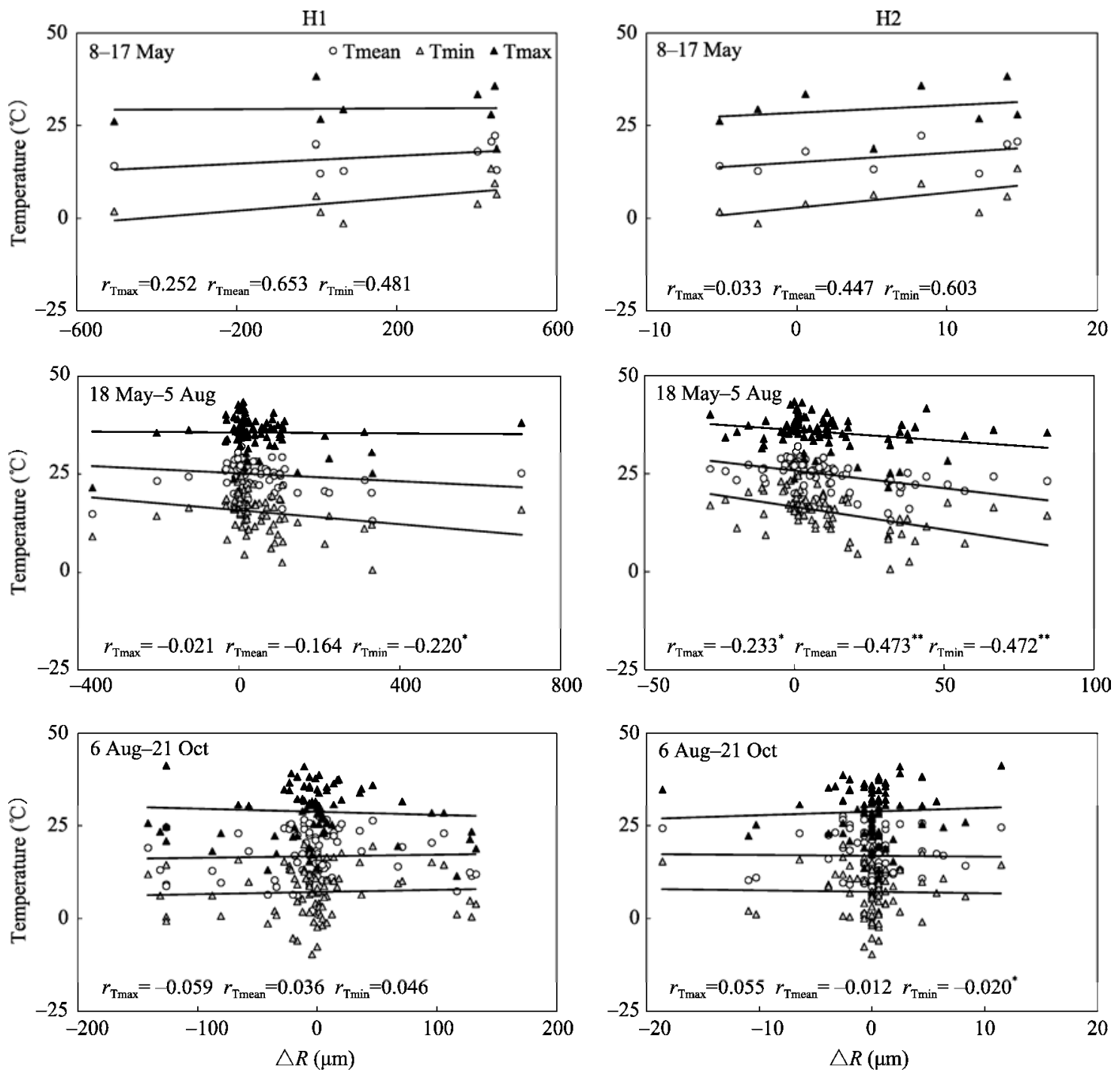

Fig. 6 Correlations between tamarisk stem diameter daily increment $(\Delta R)$ and air temperature (Tmax, Tmean and Tmin) during the 2012 growing season (left and right columns are for $\mathrm{H} 1$ and $\mathrm{H} 2$, respectively). **, correlation is significant at the 0.01 level (2-tailed); , correlation is significant at the 0.05 level (2-tailed).

mid May, however this correlation was not significant. From late May to early August, the three air temperature parameters were negatively correlated with $\Delta R$ for both samples. For H1, the correlation with minimum daily air temperature (Tmin) was strongest ( $r=$ $-0.220, P<0.05$ ). For H2, the correlations with the highest daily air temperature (Tmax) ( $r=-0.472$, $P<0.01)$ and the mean daily air temperature (Tmean) $(r=-0.473, P<0.01$ ) were highly significant; the correlation with the minimum daily air temperature (Tmin) was also significant $(r=-0.233, P<0.05)$. From early August to the end of growing season, correlations between each sample and the three air temperature parameters were weak and variable (Fig. 6).
The daily mean groundwater depth was significantly positively correlated with $\Delta R$ for both samples over the main growing season from late May to early August ( $r=0.363, P<0.01$ and $r=0.550, P<0.01$ for $\mathrm{H} 1$ and $\mathrm{H} 2$, respectively) and over the entire growing season ( $r=0.355, P<0.01$ and $r=0.496, P<0.01$ for $\mathrm{H} 1$ and $\mathrm{H} 2$, respectively) (Fig. 7).

\subsection{Tree-ring development}

The transverse sections showed that the tamarisk has semi-ring porous wood, in which the majority of the ring is comprised of early wood, and the vessel cells were primarily distributed in the early wood or massed around the last late wood (Fig. 8). The early wood cells were normally irregular polygons or round 
with an irregular arrangement, while the late wood cells were normally oblongs with a consistent arrangement. The rings were normally eccentric, thus the ring widths varied in different directions.

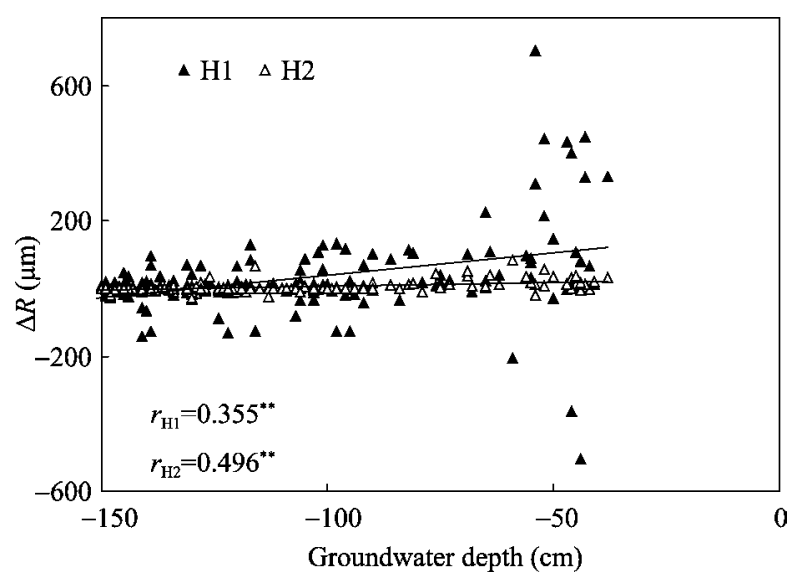

Fig. 7 Tamarisk stem diameter daily increment $(\Delta R)$ and mean daily groundwater depth in the sampling plot. **, correlation is significant at the 0.01 level (2-tailed).

The process of wood formation of tamarisk is also shown in Fig. 8. On 10 May, 1-2 vessel cells and some early wood cells had been produced, although the green staining showed incomplete lignification. On 24 May, the early wood stained red and late wood stained blue, indicating that the early wood had completed lignification but the late wood had not. By 21 June, several late wood cells had developed, but the early wood cells showed incomplete lignification. On 5 July, late wood cells were abundant, and the early wood cells showed complete lignification. On 19 July, part of the late wood cells had completed lignification, although the lignification process varied in different directions depending on eccentricity. On 16 August, the late wood cells had completed lignification.

\section{Discussion}

\subsection{Stem diameter changes and the main period of tree-ring formation}

Changes in tree stem diameter occurred due to both cambial growth and changes in water content and tension. Growth was observed as an irreversible increase in diameter while water content had a diurnal cycle (Parlange et al., 1975; Drew and Downes, 2009). The variation in radius that was measured using point
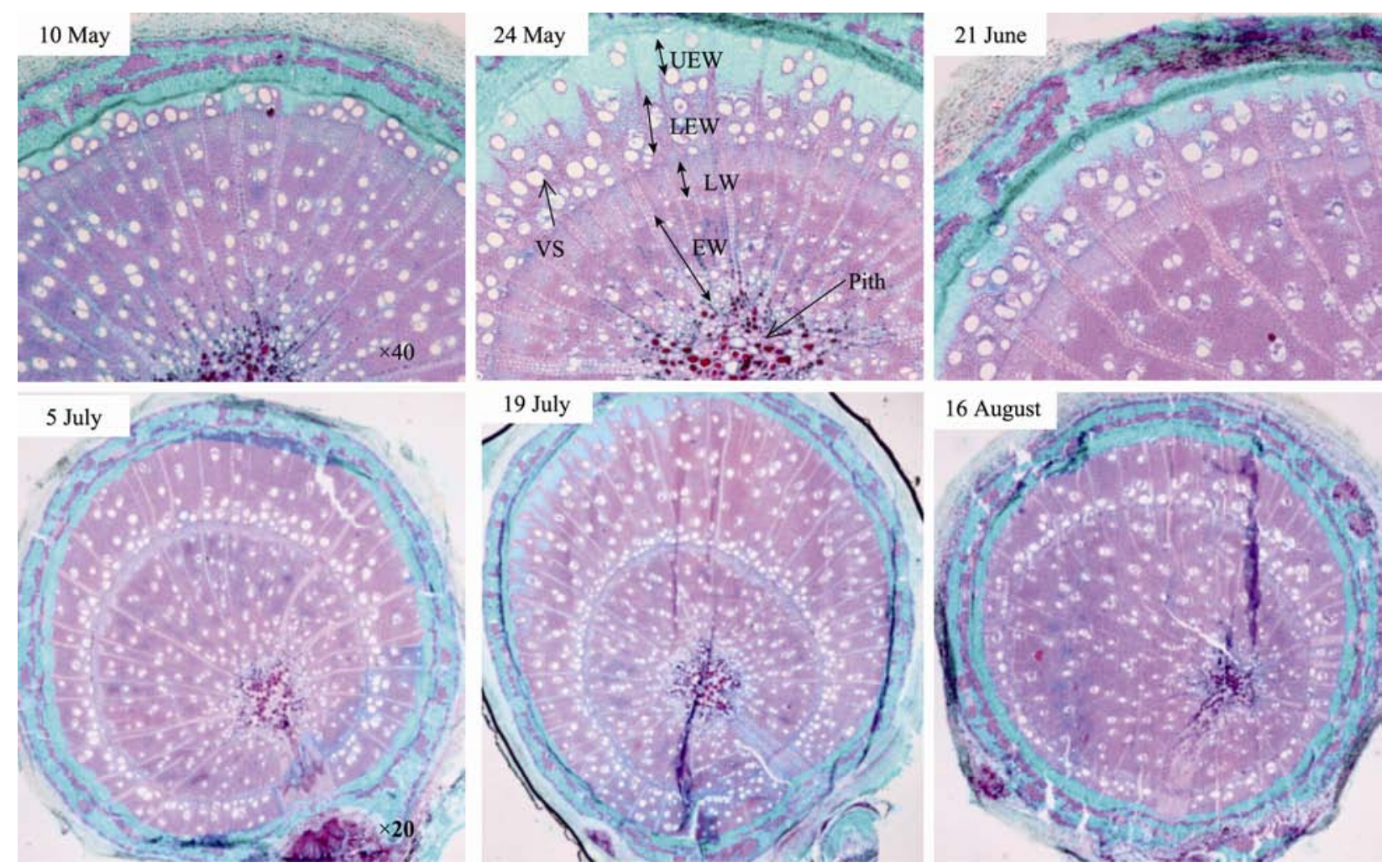

Fig. 8 Microscopy images of transverse sections of tamarisk collected during the 2012 growing season. VS, vessel cell; EW, early wood; LW, late wood; LEW, lignified early wood; UEW, unlignified early wood 
dendrometers resulted from radial growth of the whole xylem (heartwood, sapwood and new sapwood), the phloem, the cambial zone and the bark, and thus represented the overall water-related shrinkage and swelling of all of these tissues. On a diurnal scale, stem radial variation was closely linked to the water status of a tree because the time course of xylem water potential is reflected in fluctuations in stem diameter (Parlange et al., 1975; Drew and Downes, 2009). The tree stem contracts elastically during the day because of the water tension created by transpirational flows and recovers (expands) during the night because of the decrease in water tension. Observations of sap flow in tamarisk from the same area showed that the sap flow rate presented a multi-peak pattern, with sharply decreasing phenomena (Zhang et al., 2006). This phenomenon matches the pattern of diurnal variation in stem diameter observed in our study. The water status of a tree was impacted by integrated environmental factors. Therefore, the environmental factors presented varied relationships to the diurnal changes in stem diameter over the observation period (Fig. 5).

Compared with the water-related changes, the growth-induced changes in the xylem cylinder were relatively small and were generally not more than 5.5\% of the overall daily changes $(\Delta \mathrm{R}$; Offenthaler et al., 2001); however, it is not possible to separate the xylem changes from the other changes (Dobbs and Scott, 1971; Molz and Klepper, 1973; Brough et al., 1986; Zweifel et al., 2000; Daudet et al., 2005). Cell enlargement was regarded as the major driving force for radial stem increase (Deslauriers et al., 2003). Cambial cell division represented only a small amount of radial change (Gruber et al., 2010), and secondary wall thickening and lignification took place inside enlarged cells and were therefore not expressed as a radial increase.

From late May to late June, the sap flow was very high, while the sap flow from late June to late August was less than $30 \%$ of the initial flow, decreasing progressively to as low as 15\% (Zhang et al., 2006). Along with the irreversible process of the cell division in the cambial zone and cell lignification in the early and late wood (Fig. 6), the $\Delta R$ was primarily found to be positive $(\Delta R+)$ during the main growth period (from late May to early August) (Fig. 4b). This result indicated that the tree-ring development of tamarisk contributed largely to the changes in stem diameter over this period. With the decrease in sap flow and the maturation of the xylem and phloem cells, the amplitude of $\Delta R$ became gradually smaller. Thus, during the growing season, the diurnal variation in stem diameter was always affected by the water status of the tree. During the main growing period, the actual stem growth played a large part in the total changes in stem diameter.

The cumulative radial increment of trees in boreal and temperate vegetation zones typically follows an S-shaped curve, with slow increments during spring and early summer, fast increments in midsummer, and gradually decreasing rates towards autumn (Henttonen et al., 2009). Our study, which examined the cumulative stem diameter growth curves and the dynamics of xylem ring formation, showed that increment creation in tamarisk began in late May, reached its peak in early July and ceased in early August. Similarly, the stem radial growth of Larix principis-rupprechtii on Liupan Mountain, northwestern China, had the fastest growth during June and July with a growth rate of 27.0 to $44.2 \mu \mathrm{m} /$ day versus a slow growth rate of less than $10.0 \mu \mathrm{m} /$ day from August to September (Xiong et al., 2007). Liang et al. (2009) studied the seasonal cambial activity of Chinese pine (Pinus tabulaeformis Car) in northern China using the micro-coring method and showed that cell differentiation and growth started in late May, followed by a period of rapid development in June and July.

Studies of Picea abies, Abies alba, Fagus sylvatica, Quercus robur and Castanea sativa in Europe showed that $75 \%$ of the tree ring had formed before late June, indicating that the early wood had formed completely, that a portion of the early wood would change into late wood over subsequent months, and that, by mid August, all of the new xylem cells had differentiated completely from the cambium. In general, the period from late May to early July was the most active period for cell differentiation, and cambial activity subsequently slowed during periods of high temperatures, after which the cambium became active again from mid September to the end of the growing season (Werf et al., 2007; Cufar et al., 2008a, b, 2011). The differences among species in the duration of ring formation can be ascribed to genetic differences, differences in tree age and microsites, and year to year variation in climatic conditions. For 
example, the cambial zone of Fagus orientalis in Iran became active from late March to early April, with cells differentiating intensely from mid April to early June (with the highest daily rate of stem radial growth occurring at the beginning of June), followed by slower growth through the end of the growing season in late September or the beginning of October (Oladi et al., 2011).

\subsection{Limiting factors for tree ring formation}

Our results showed that the higher temperatures during the early growing season improved stem diameter growth, but that increasing temperatures during the middle of the growing season began to limit the stem diameter growth when temperatures became too high. This conclusion is based on the significant negative correlation between the three air temperature parameters and $\Delta R$ (Fig. 6). When temperatures began decreasing in the later part of the growing season, the water deficit of a tree was reduced; there was no clear correlation between air temperature parameters and $\Delta R$ during this time period.

The significant positive relationships between groundwater depth and $\Delta R$ indicated that groundwater depth controlled the stem diameter increment over the entire growing season (Fig. 7). This is consistent with previous ecophysiological and dendroclimatological studies of this species conducted within the study area and in other similarly areas. Anderson (1977) suggested that because tamarisk is a phreatophyte that can reach the groundwater table with its deep roots, groundwater can provide over $90 \%$ of all necessary water out of all water sources, which also include soil water, rainfall and river water (Zhao et al., 2008). After analyzing changes in soil water content and the distribution of roots in tamarisk stands before and after irrigation, Zeng et al. (2002) deduced that the increased transpiration of tamarisk following irrigation resulted from increased utilization of deep soil water, but did not result from increased water content in the upper layer of the soil. A study of isotopic variation in the xylem cellulose of the tamarisk showed that the water source for saplings was mainly local precipitation, whereas young and mature trees primarily utilized groundwater to support root system development (Yang et al., 1996). Through the study of the ecohydrological response of tamarisk along the shores of Juyan Lake in the same study area, Xiao and Xiao
(2007) showed that fluctuations in the lake water level during the growing season (May-August) was primarily responsible for variations in the radial growth of tamarisk. Availability of water is the main factor that limits plant growth in arid regions, thus high temperatures will magnify the negative impacts on radial stem variation of tamarisk due to the creation of water deficits when the groundwater depth becomes deep enough that the soil moisture above this level can no longer meet the needs of the trees (Xiao and Xiao, 2007). The results of this study suggest that the groundwater depth was the primary limiting factor to the formation of tree rings in tamarisk.

\section{Conclusions}

The diurnal changes in tamarisk stem diameter exhibited a multi-peak pattern, and this diurnal rhythm was controlled by tree water status, which was impacted by the integration of several environmental factors. During the primary tree-ring formation period, the real growth of wood and bark, which is an irreversible process, accounted for a large part of the stem diameter diurnal increment. Tree-ring formation occurred primarily from late May to early August, and groundwater depth was the primary factor controlling radial growth. The annual rings of tamarisk can be used to reconstruct processes that determine the regional water regime, such as river runoff and fluctuations in groundwater depth. For the management of desert riparian forests, suitable groundwater depths must be maintained in the spring and summer to sustain tree health and a suitable stand structure.

\section{Acknowledgements}

This work was funded by the National Natural Science Foundation of China (40971032, 91125026).

\section{References}

Anderson J E. 1977. Transpiration and photosynthesis in saltcedar. Hydrology and Water Resources in Arizona and the Southwest, 7: 125-131.

Antonova G F, Stasova V V. 1993. Effects of environmental factors on wood formation in Scots pine stems. Trees, 7: 214-219.

Antonova G F, Stasova V V. 1997. Effects of environmental factors on wood formation in larch. Trees, 11: 462-468.

Bäucker E, Bues C T, Vogel M. 1998. Radial growth dynamics of spruce (Picea abies) measured by micro-cores. IAWA Journal, 19: 301-309. 
Bouriaud O, Leban J M, Bert D, et al. 2005. Intra-annual variations in climate influence growth and wood density of Norway spruce. Tree Physiology, 25: 651-660.

Brough D W, Jones H G, Grace J. 1986. Diurnal changes in water content of the stems of apple trees, as influenced by irrigation. Plant Cell \& Environment, 9: 1-7.

Cufar K, Prislan P, Gricar J, et al. 2008a. Cambial activity and wood formation in beech (Fagus sylvatica) during the 2006 growth season. Wood Research, 53: 1-12

Cufar K, Prislan P, Luis M, et al. 2008b. Tree-ring variation, wood formation and phenology of beech (Fagus sylvatica) from a representative site in Slovenia, SE Central Europe. Trees, 22: 749-758

Cufar K, Cherubini M, Gricar J, et al. 2011. Xylem and phloem formation in chestnut (Castanea sativa Mill.) during the 2008 growing season. Dendrochronologia, 29: 127-134.

Daudet F, Ameglio T, Cochard H, et al. 2005. Experimental analysis of the role of water and carbon in tree stem diameter fluctuations. Journal of Experimental Botany, 56: 135-144.

Deslauriers A, Morin H, Urbinati C, et al. 2003. Daily weather response of balsam fir (Abies balsamea (L.) Mill.) stem radius increment from dendrometer analysis in the boreal forests of Quebec (Canada). Trees, 17: 477-484.

Deslauriers A, Rossi S, Anfodillo T. 2007. Dendrometer and intra-annual tree growth: what kind of information can be inferred? Dendrochronologia, 25: 113-124.

Dobbs R C, Scott D R M. 1971. Distribution of diurnal fluctuations in stem circumference of Douglas fir. Canadian Journal of Forest Research, 1: 80-83.

Downes G M, Wimmer R, Evans R. 2002. Understanding wood formation: gains to commercial forestry through tree-ring research. Dendrochronologia, 20: 37-51.

Downes G M, Drew D, Battaglia M, et al. 2009. Measuring and modeling stem growth and wood formation: an overview. Dendrochronologia, 27: 147-157.

Drew D, Downes G M. 2009. The use of precision dendrometers in research on daily stem size and wood property variation: a review. Dendrochronologia, 27: 159-172.

Fonti P, Solomonoff N, García-González I. 2007. Earlywood vessels of Castanea sativa record temperature before their formation. New Phytologist, 173: 562-570.

Frankenstein C, Eckstein D, Schmitt U. 2005. The onset of cambium activity - A matter of agreement? Dendrochronologia, 23: 57-62.

Fritts H C. 1962. The relevance of dendrographic studies to tree ring research. Tree Ring Bulletin, 24(1-2): 9-11.

García-González I, Eckstein D. 2003. Climatic signal of earlywood vessels of oak on a maritime site. Tree Physiology, 23: 497-504.

Gruber A, Strobl S, Veit B, et al. 2010. Impact of drought on the temporal dynamics of wood formation in Pinus sylvestris. Tree Physiology, 30: 490-501.

Henttonen H M, Makinen H, Nojd P. 2009. Seasonal dynamics of the radial increment of Scot pine and Norway spruce in the southern and middle boreal zones in Finland. Canada Journal of Forest research, 39: 606-618.

Herzog K, Hasler M, Thum R. 1995. Diurnal changes in the radius of a subalpine Norway spruce stem: their relation to the sap flow and their use to estimate transpiration. Trees, 10: 94-101.

Horacek P, Slezingerova J, Gandelova L. 1999. Effects of environment on the xylogenesis of Norway spruce (Picea abies [L.] Karst.). In: Wimmer R \&Vetter R E. Tree-ring Analysis: Biological, Methodological and Environmental Aspects. Oxon, UK: CAB International, 33-53.

Li Y, Liang E Y, Shao X M. 2008. Variations of Picea crassifolia tree-ring cell structure and their implications to past climate in eastern margin of Qaidam Basin, Northwest China. Chinese Journal of Applied Ecology, 19: 524-5326.

Liang E Y, Eckstein D, Shao X M. 2009. Seasonal cambial activity of relict Chinese Pine at the northern limit of its natural distribution in North China - Exploratory results. IAWA Journal, 30: 371-378.

Mäkinen H, Nöjd P, Saranpaa P. 2003. Seasonal changes in stem radius and production of new traeheids in Norway spruce. Tree Physiology, 23: 959-968.

Mäkinen H, Seo J W, Nöjd P, et al. 2008. Seasonal dynamics of wood formation: a comparison between pinning, microcoring and dendrometer measurements. European Journal of Forest Research, 127: 235-245.

Marion L, Gričar J, Oven P. 2007. Wood formation in urban Norway maple trees studied by the micro-coring method. Dendrochronologia, 25: $97-102$

Molz F J, Klepper B. 1973. On the mechanism of water-stress-induced stem deformation. Agronomy Journal, 65: 304-306.

Nöjd P, Henttonen H M, Mäkinen H. 2008. Increment cores from the Finnish National Forest Inventory as a source of information for studying intra-annual wood formation. Dendrochronologia, 26: 133-140.

Offenthaler I, Hietz P, Richter H. 2001. Wood diameter indicates diurnal and long-term patterns of xylem water potential in Norway spruce. Trees, 15: 215-221.

Oladi R, Pourtahmasi K, Eckstein D, et al. 2011. Seasonal dynamics of wood formation in Oriental beech (Fagus orientalis Lipsky) along an altitudinal gradient in the Hyrcanian forest, Iran. Trees, 25: 425-433.

Parlange J Y, Turner N C, Waggoner P E. 1975. Water uptake, diameter change, and nonlinear diffusion in tree stems. Plant Physiology, 55: 247-250.

Plomion C, Leprovost G, Stokes A. 2001. Wood formation in trees. Plant Physiology, 127: 1513-1523.

Rossi S, Deslauriers A, Anfodillo T, et al. 2006a. Conifers in cold environments synchronize maximum growth rate of tree-ring formation with day length. New Phytologist, 170: 301-310.

Rossi S, Deslauriers A, Anfodillo T. 2006b. Assessment of cambial activity and xylogenesis by microsampling tree species: an example at the alpine timberline. IAWA Journal, 27: 383-394.

Rossi S, Deslauriers A. 2007. Intra-annual time scales in tree rings. Dendrochronologia, 25: 75-77.

Rossi S, Deslauriers A, Anfodillo T, et al. 2007. Evidence of threshold temperatures for xylogenesis in conifers at high altitudes. Oecologia, 152: 1-12.

Schmitt U, Jalkanen R, Eckstein D. 2004. Cambium dynamics of Pinus sylvestris and Betula spp. in the northern boreal forest in Finland. 
Silva Fennica, 38: 167-178.

Schmitt U, Möller R, Eckstein D. 2000. Seasonal wood formation dynamics of beech (Fagus sylvatica L.) and black locust (Robinia pseudoacacia L.) as determined by the "pinning” technique. Journal of Applied Botany, 74: 10-16.

Schweingruber F H. 2007. Wood Structure and Environment. New York: Springer-Verlag Berlin Heidelberg, 270.

Tardif J, Flannigan M, Bergeron Y. 2001. An analysis of the daily radial activity of 7 boreal tree species, North-western Québec. Environment Monitor and Assessment, 67: 141-160.

Turcotte A, Morin H, Krause C, et al. 2009. The timing of spring rehydration and its relation with the onset of wood formation in black spruce. Agricultural and Forest Meteorology, 149: 1403-1409.

Vaganov E A, Hughes M K, Shashkin A V. 2006. Growth dynamics of conifer tree rings: images of past and future environments. In: Ecological Studies. Berlin: Springer-Verlag Berlin Heidelberg, 183.

Werf V D, Sass-Klaassen G W, Mohren U, et al. 2007. The impact of the 2003 summer drought on the intra-annual growth pattern of beech (Fagus sylvatica L.) and oak (Quercus robur L.) on a dry site in the Netherlands. Dendrochronologia, 25: 103-112.

Xiao S C, Xiao H L. 2007. Radial growth of Tamarix ramosissima responds to changes in the water regime in an extremely arid region of northwestern China. Environmental Geology, 53: 543-552.

Xiong W, Wang Y H, Yu P T, et al. 2007. Growth in stem diameter of Larix principis-rupprechtii and its response to meteorological factors in the south of Liupan Mountain, China. Acta Ecologica Sinica, 27: 432-441.

Yang W B, Spencer R J , Krouse H R. 1996. Stable sulfur isotope hydrogeochemical studies using desert shrubs and tree rings, Death Valley, California, USA. Geochimica \& Cosmochimica Acta, 60: 3015-3022.

Zeng F J, Andera F, Li X Y, et al. 2002. A preliminary study on the effect of irrigation on water physiology of Tamarix ramosissima in Cele Oasis. Chinese Journal of Applied Ecology, 13: 849-853.

Zhang X Y, Kang E S, Si J H, et al. 2006. Studies on the Water Consumption Rhythm of Tamarix spp in Ejina Oasis. Journal of Arid land resources and Environment, 20: 159-162.

Zhao L J, Xiao H L, Cheng G D, et al. 2008. A preliminary study of water sources of riparian plants in the lower reaches of the Heihe River basin. Acta Geoscientica Sinica, 29: 709-718.

Zweifel R, Item H, Häsler R. 2000. Stem radius changes and their relation to stored water in stems of young Norway spruce trees. Trees, 15: 50-57. 